\title{
Pisacano Leadership Foundation Names 2015 Pisacano Scholars
}

\section{Jane Ireland}

The Pisacano Leadership Foundation, the philanthropic arm of the American Board of Family Medicine, recently selected its 2015 Pisacano Scholars. These 6 medical students follow in the footsteps of 100 scholar-alumni who are practicing physicians and 19 current scholars who are enrolled in medical schools or family medicine residency programs across the country. The Pisacano Leadership Foundation was created in 1990 by the American Board of Family Medicine in tribute to its founder and first executive director, Nicholas J. Pisacano, MD (1924-1990). Each Pisacano Scholar has demonstrated the highest level of leadership, academic achievement, communication skills, community service, and character and integrity.

Paige Bennett, a 2015 Pisacano Scholar, is a fourth-year medical stu-

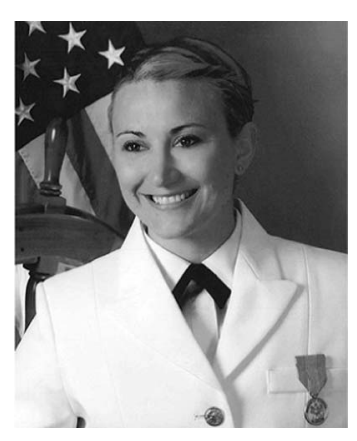
dent at the University of Colorado School of Medicine. Paige graduated with distinction from the University of Colorado, Boulder, with a bachelor of arts in integrative physiology.

As an undergraduate, Paige received multiple scholarships, including the Puksta Scholarship, which is awarded to students who catalyze positive change in the campus culture and in local communities. She served on the student government board at the University of Colorado, Boulder, first as secretary for a year and then as co-chair for 2 years. She also worked throughout college as a medical assistant at a free teenage gynecology clinic, performing women's annual examination interviews

Conflict of interest: The author is the communications editor for the ABFM. and providing counseling on safe sex and healthy behaviors.

Paige developed and has been involved in a teen obesity community-based research project since beginning medical school. The inspiration for this project came from repeated experiences of witnessing conversations between health care providers and teenagers that humiliated the teens, rather than empowering them to make better choices. As principle investigator, Paige's responsibilities include designing the project, providing ongoing teen advisory board recruitment and involvement, maintaining the budget and obtaining grant funding, and sharing results with health care professionals. In addition, Paige has volunteered with several other organizations, including a year as a medical volunteer with a community center providing basic health care for the uninsured and homeless. She has received multiple awards since beginning medical school, including a Medical Student Council Innovations Award and a Student Award for Exemplary Student Engagement.

Paige's current work with a rural family physician on an integrated, longitudinal rural clerkship has solidified her conviction to be a broad-scope rural family doctor. As a military scholar through the Navy Health Professions Scholarship Program, Paige has committed to at least 4 years of active duty and 4 years in reserves following the completion of training. As the granddaughter of a military veteran, Paige quickly realized the greatest way she could serve was to provide medical care for sailors and their families who are sacrificing for our country. As a practicing naval physician, Paige plans to further develop leadership proficiency as a public health and preventive care officer, to practice advanced teaching methods as a medical student educator, and to perfect clinical practice competencies. Following her military career, Paige intends to pursue rural medicine where she can be a town doctor and community liaison who supports the 
health care needs of her community, provides exceptional primary care for her patients, and continues to promote the future of family medicine through medical student education.

Margaret (Maggie) Chen, a 2015 Pisacano Scholar, is a fourth-year का medical student at David Geffen School of Medicine at the University of California, Los Angeles (UCLA). She graduated with honors from Stanford University, earning degrees in both comparative studies in race and ethnicity, and human biology. Maggie also is pursuing a concurrent master of public policy degree at UCLA's Luskin School of Public Affairs.

Maggie has won multiple awards for her leadership skills and dedication to community service. While at Stanford, she was recognized with the Excellence in Honors Thesis Presentation award, and an award for Community Engagement upon graduation. She served as a counselor with the Stanford HIV Peer Counseling Program and was later promoted to program coordinator. Maggie also served as chair of the Multiracial Identified Community at Stanford. While studying abroad in Cape Town, South Africa, Maggie researched gender-based HIV testing at a men's clinic. While there, she also volunteered as a group leader of 10 middle school peer educators in a local township. She later traveled to Papua New Guinea with a team of Stanford physicians, functioning as a medical student in the team's makeshift clinics.

After graduation from Stanford, Maggie served as a John Gardner Fellow in Public Service with the White House Council on Women and Girls. Mentored by senior White House officials, she coordinated programs that engage girls in science and math. While completing her fellowship, Maggie also aided in efforts to connect the White House with health advocacy groups, including those representing physicians and patients. Before medical school, Maggie developed leadership programs for Crittenton Services of Greater Washington, DC, a nonprofit organization that serves at-risk young women and teen mothers.
Since her first year of medical school, Maggie has been involved with the newly developed Primary Care Preceptor Continuity Program intended for students interested in primary care. She has also been involved with UCLA's Family Medicine Interest Group since her first year of medical school, first serving as co-president and currently as senior advisor. Maggie helped found Primary Care Progress at UCLA, an organization that works to bring together the next generation of primary care providers. At the end of her second year of medical school, Maggie was voted by her class as the most likely to improve health care and the health care system. Maggie was recently inducted into UCLA's inaugural Gold Humanism Honor Society.

Maggie's vision for her future career in family medicine is to provide effective, engaging primary care for women, while promoting the role of family physicians in women's lives. She also hopes to advise legislators and advocate for policies that support women's health.

Trevor Dickey, a 2015 Pisacano Scholar, is a fourth-year medical student at Duke University School of Medicine. He graduated from the University of Washington with a bachelor of science in biochemistry. During his third year of independent study in the Duke curriculum, Trevor earned his master of public health from the University of North Carolina Gillings School of Global Public Health.

As an undergraduate, Trevor was a member of the dean's list his last 3 years of college and was elected to the Phi Lamda Upsilon Chemical Honor Society his senior year. Trevor worked as a researcher under the mentorship of Pierre Mourad, PhD, in the Department of Neurosurgery during his last 3 years of undergraduate education. His research resulted in multiple publications, including in Biomedical Optics Express. Trevor was awarded the Mary Gates Research Scholarship in support of his research. Following his undergraduate career, Trevor continued his work with Dr. Mourad for another year.

Trevor was one of a select group of students admitted to Duke's inaugural class in the Primary Care Leadership Track. Through this program, 
Trevor has gained experience working with the underserved through programs such as Local Access to Coordinated Health care, a case management program for the uninsured in Durham County. There he worked with a program designed to assist homeless adults with applications for disability. During his first year of medical school, Trevor was elected as class president. As an Albert Schweitzer Service Fellow last year, Trevor cofounded the Duke chapter of the Refugee Health Initiative, which pairs health professions students with newly resettled refugees over the course of a semester. Last year the program had 20 volunteers and served 13 families. This past year, Trevor worked on a pilot trial with a health services laboratory researching medication adherence among a Medicaid population using a telehealth messaging program. Trevor has been a member of Duke's Family Medicine Interest Group since beginning medical school and currently serves as treasurer. Two years ago, Trevor was elected by his peers to the Alpha Omega Alpha Medical Honor Society.

Trevor would like to maintain a strong clinical presence in his career by working at one of the nation's many federally qualified health centers, while also becoming involved in a public health organization. He is excited to soon join the specialty of family medicine because it recognizes the complimentary nature of population health and patient well-being.

Elizabeth Looney, a 2015 Pisacano Scholar, is a fourth-year medical stu-

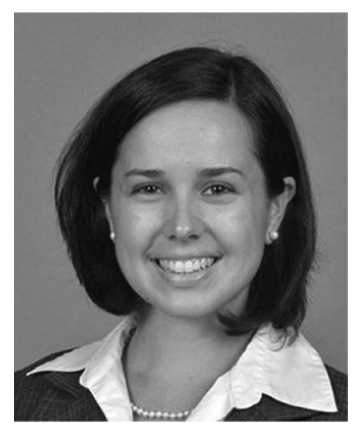
dent at Northeast Ohio Medical University. Elizabeth graduated summa cum laude from the University of San Francisco with bachelor of arts degrees in psychology and Latin American studies. She received her master of arts in community social psychology from the University of Massachusetts, Lowell.

As an undergraduate, Elizabeth volunteered as resident advisor and community head with the Martín-Baró Scholars Community, a living/learning community of students dedicated to social justice and academics. She was recognized for her work with the Jesuit Leadership Award from the University of
San Francisco. Elizabeth also worked throughout college as a teaching and program assistant in the psychology department at the University of San Francisco. She spent her junior year in San Salvador, El Salvador, with the Casa de la Solidaridad, a study abroad program run through Santa Clara University. As a community coordinator, Elizabeth was responsible for managing 1 of 3 community houses, mentoring students and providing general community leadership. Serving later as codirector of the Casa's summer medical program, Elizabeth planned and executed two 5-week summer medical immersion programs for US premedical students in El Salvador.

While completing her master's degree at the University of Massachusetts, Elizabeth interned with the Lowell Community Health Center in the HIV department. She worked collaboratively with the HIV staff, including administrators, health care providers, and peer support, to deliver social and medical care to inner-city HIV-positive patients. She also worked as a graduate assistant with the psychology department during this time.

Before medical school, Elizabeth worked as a program manager where she managed federally funded after-school tutoring programs in 4 lowperforming Cleveland public elementary schools. She also spent 2 months as a volunteer, living and working with the Sisters of Charity of Cincinnati at their clinic in Anapra, Mexico, caring for children with special needs and their families.

During her first year of medical school, Elizabeth was selected to receive the Choose Ohio First Scholarship. This competitive award is granted by the State of Ohio to students who exemplify leadership and commitment to primary care in Ohio. She was also 1 of 6 medical students chosen to participate in Akron General's Clinical Rotations and Future Training program, a premier 8-week summer program designed for students interested in a career in primary care. Last year, nominated by Northeast Ohio Medical University, Elizabeth was selected and featured in Crain's Cleveland Business "Who to Watch in Medicine, 2014." Earlier this year, Elizabeth was elected to the national medical honor society Alpha Omega Alpha, as well as the Gold Humanism Honor Society.

Elizabeth believes the full-scale responsibility of a family physician extends beyond the office door to be an agent for change in the community and beyond. The job of a family physician - to care for 
the whole patient—necessarily means caring for the whole context in which they live.

Sara Martin, a 2015 Pisacano Scholar, is a fourth-year medical stu-

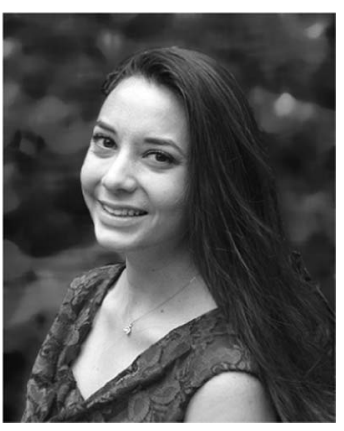
dent at Harvard Medical School. She graduated from Mount Holyoke College with bachelor of arts degrees in biochemistry and history. She recently completed her master of science in comparative social policy at Oxford University and is currently working on policy for the Health Foundation in London.

At Mount Holyoke, Sara received numerous scholarships and awards, including a 4-year Mount Holyoke Leadership Scholarship and an American Chemistry Society scholarship. After graduation she received the Kelly Sottile Community Service Award, which honors a student who has made significant contributions to the community outside the gates of Mount Holyoke by consistently demonstrating personal commitment and sensitivity to human needs. At Mount Holyoke, Sara served as co-chair of Creating Awareness and Unity for Social Equity, the largest community service organization on campus, where she organized and assisted with approximately 20 community service projects and 10 annual events. During her undergraduate studies at Mount Holyoke, Sara also worked as a general chemistry teaching assistant. Upon graduation she spent a year and a half teaching chemistry at an underprivileged urban high school in Springfield, Massachusetts.

At Harvard, Sara received the Linnane Scholarship for Leadership and was named a Primary Care Master's Scholar. She also received the Dean's Community Service Award during her third year of medical school. Through her involvement with Primary Health Care International, Sara has been a part of developing a leadership program for students interested in global health. She also has been involved in writing grants and applying for nonprofit status for this organization. For a summer project after her first year of medical school, Sara traveled to Zimbabwe as part of research for Partners in Health, where she evaluated the utility of the organization's Program Management Guide through questionnaires and in-depth interviews with members of new and established nongovernmental organizations in both Boston and Zimbabwe.

Sara was a co-leader of Harvard's Family Medicine Interest Group and a member of the Student Leadership Committee at the Center for Primary Care. During the second half of medical school, she applied for and received 2 Agents of Change Challenge Grants from the Center for Primary Care to use the resources of Cambridge Health Alliance to establish an innovative school-based health center, now named the Starr Center. Sara served as program manager of the Starr Center, which provides comprehensive health services within a local high school. Sara has presented a number of posters, including most recently at the Society for Teachers of Family Medicine's Conference on Medical Student Education, for which she also received a scholarship.

As a future family physician, Sara's mission is to advocate for her patients' health by examining and improving the intersection between health care and education.

Diana Wohler, a 2015 Pisacano Scholar, is a fourth-year medical stu-

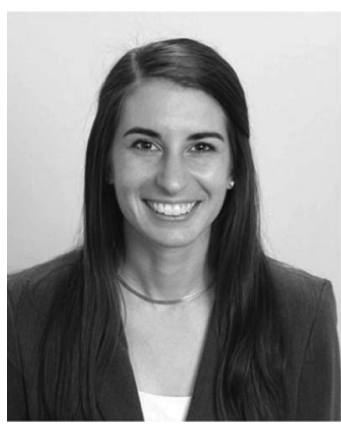
dent at Harvard Medical School. She graduated from Johns Hopkins University with a bachelor of science in molecular and cellular biology and a minor in music. She was a member of the National Society of Collegiate Scholars and was inducted into Phi Beta Kappa her senior year.

As a college student, Diana volunteered weekly for 4 years at the Baltimore Rescue Mission Clinic, a primary care clinic predominantly for homeless men. It was this experience and the longitudinal relationships she formed that inspired Diana to pursue a career in primary care. She served as the community service coordinator for the Women's Pre-Health Leadership Society at Johns Hopkins, furthering her connection with the Baltimore Rescue Mission Clinic. She was a teaching assistant for a genetics course and organic chemistry laboratory. She also was a member of the Women's Ultimate 
Frisbee team at Johns Hopkins, serving as co-captain her senior year.

At Harvard, Diana has been an active member of the Family Medicine Interest Group and served as the group's leader for a year. She served as a research and life mentor at a high school enrichment program and recently as a preceptor and bedside teacher for first-year medical students with Harvard's patient interviewing course. Diana served as the director of patient education for the patient education and counseling program at a student-run faculty collaborative clinic, Crimson Care Collaborative's Beth Israel Deaconess Medical Center site, which focuses on chronic medical conditions. She then served as the senior director at Crimson Care Collaborative's Cambridge Health Alliance site, Harvard's first student-run family medicine clinic, which she co-founded after her third year of medical school. As senior director, Diana's responsibilities included facilitating clinic flow, directing process improvement initiatives, coordinating health professions students and faculty preceptors, and facilitating didactic instruction. In her first year at Harvard, Diana was selected as an inaugural member of the Student Leadership Committee of the Harvard Center for Primary Care. She served as family medicine committee chair last year and is currently serving as coleader of the student leadership committee. In this position, Diana is responsible for the leadership training and development of 21 medical and dental students, the completion of committee projects and deliverables, and maintaining a relationship between the student and faculty members for the Center for Primary Care.

Diana has presented at numerous conferences, including the Society of Teachers in Family Medicine's National Conference. Her current research interest is in leadership training for medical students. Diana intends to incorporate medical education into her future practice, delivering interprofessional, team-based care to her patients. 